\title{
24-Month adherence, tolerance and efficacy of once-a-day antiretroviral therapy with didanosine, lamivudine, and efavirenz in African HIV-1 infected children: ANRS 12103/12167
}

*Hien $\mathrm{H}^{1}, 2$, Meda $\mathrm{N}^{1}$, Diagbouga $\mathrm{S}^{2}$, Zoure $\mathrm{E}^{3}$, Yaméogo $\mathrm{S}^{3}$, Tamboura $\mathrm{H}^{3}$, Somé $\mathrm{J}^{3}$, Ouiminga $\mathrm{A}^{1}$, Rouet $\mathrm{F}^{4}$, Drabo $\mathrm{A}^{1}$, Hien $\mathrm{A}^{3}$, Nicolas $\mathrm{J}^{5}$, Chappuy $\mathrm{H}^{6}$, Van de Perre $\mathrm{P}^{7}$, Msellati $\mathrm{P}^{8}$, Nacro $\mathrm{B}^{3}$

1. Unité de recherche Santé de la Reproduction VIH et Maladies Associées, Centre MURAZ, Bobo-Dioulasso, Burkina Faso

2. Institut de recherche en sciences de la santé, Bobo-Dioulasso, Burkina Faso

3. Département de pédiatrie, CHU Souro Sanou, Bobo-Dioulasso, Burkina Faso.

4. CIRMF, Franceville Gabon

5. Département de Pédiatrie, CHU, Montpellier, France.

6. Université Paris Descartes, Paris, France

7. INSERM U 1058, Infection by HIV and by agents with mucocutaneous tropism: from pathogenesis to prevention; Université Montpellier 1; CHU Montpellier, Département de bactériologievirologie, Montpellier, France

8. UMI 233, IRD/Université de Montpellier 1/Université Cheick Anta Diop Dakar/Université de Yaoundé 1, BP 1857, Yaoundé, Cameroun

\begin{abstract}
Background: There is no data on long-term benefit of once-a-day antiretroviral therapy (ART) with combination of DDI, 3TC and EFV to allow its use in future therapeutic strategies.

Objectives: To assess 24-month immuno-virological, adherence, tolerance, and effectiveness of a once-a-day ART with DDI, 3TC and EFV.

Methods: A phase 2 open trial including 51 children aged from 30 months to 15 years, monitored a once-a-day regimen for 24 months from 2006 to 2008 in the Departement de Pediatrie du CHUSS, at Bobo-Dioulasso in Burkina Faso. We tested immunological and virological response, adherence, tolerance and resistance of the treatment.

Results: Children with CD4 >25\% at 24 months were $67.4 \%$ (33/49) CI 95\% [54\%, 80\%].The proportion of children with viral plasma RNA $<300 \mathrm{cp} / \mathrm{ml}$ at 24 months of treatment was $81.6 \%$ (40/49) CI [68.0\% 91.2\%]. Good adherence was obtained with more than $88 \%$ adherence $>95 \%$ over the 24 months. Drugs were well tolerated. Conclusions: Given the limited number of antiretroviral drugs available in Africa and the inadequacy of laboratory monitoring in support program, once-a-day treatment and especially the DDI-based combination strategies could be an attractive operational option.
\end{abstract}

Key words: once-a-day therapy, Didanosine, Lamivudine, and Efavirenz, child.

African Health Sciences 2013; 13(2): 287 - 294 http://dx.doi.org/10.4314/ahs.v13i2.13

\section{Introduction}

With more than $95 \%$ of worldwide infections affecting children, pediatric HIV-1 infection constitutes a public health challenge in developing countries ${ }^{1-3}$. In 2008, it was recommended that early antiretroviral therapy started with children born to

\footnotetext{
*Corresponding author:

Hervé Hien

Unité de recherche Santé de la Reproduction

VIH et Tuberculose

01 BP 390 Centre URAZ

Bobo-Dioulasso, Burkina Faso

Tel.: 0022670245455

Email: hien_herve@hotmail.com
}

HIV positive mothers reduce mortality and morbidity related to $\mathrm{HIV}^{4}$. Facilitation of antiretroviral therapy (ART) in children remains a priority in order to optimize adherence and efficacy. Once-a-day antiretroviral therapy may be an option regimen. This regimen may represent a significant advantage in terms of quality of life, adherence to long-term therapy, minimizing risk of treatment errors, and reduction of inappropriate prescriptions ${ }^{5}$. Once-a-day combination with Didanosine, Lamivudine and Efavirenz was previously studied

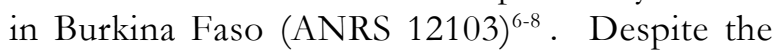
satisfactory pharmacokinetics of DDI, 3TC and 
EFV, target DDI plasma concentrations were not always reached in some of the youngest children.. Dose adaptation of the three drugs for the youngest children $(<15-17 \mathrm{~kg}$ in weight) would probably improve efficacy. Results for the 12-month followup showed a good immuno-virological efficacy ${ }^{9}$. Forty one percent $(41 \%)$ of the 49 children had a CD $4 \%$ of more than $25 \%$ at 12 months, while $81 \%(39 / 49)$ children had a viral load $<300$ RNA $\mathrm{cp} / \mathrm{ml}$ at 12 months However, there were no data on long-term benefit of this treatment to justify its use in future therapeutic strategies.

In this study, we report our findings of tolerance, adherence, resistance and efficacy after 24 months of once-a-day antiretroviral treatment. These results could help future choices of pediatric treatment in Africa.

\section{Methods \\ Study design}

We conducted a phase 2 open clinical trial evaluating the pharmacokinetics, tolerance, adherence, immunovirological efficacy of the DDI $+3 \mathrm{TC}+\mathrm{EFV}$ combination at 12 and 24 months. Fifty one children infected with HIV-1 followed up in the ANRS 12103 trial ${ }^{9}$ were included and monitored for one additional year from 2007 to 2008 in the Department of pediatric of Centre Hospitalier Universitaire Sanou Souro in Bobo-Dioulasso, Burkina Faso.

\section{Study population and eligibility criteria}

Eligibility criteria were: i) Children infected with HIV-1 between the ages of 30 months and 15 years, and weighting more than 10 kilograms, ii) naive to any antiretroviral treatment except for the prevention of mother-to-child transmission, iii) children $<5$ years: clinical stage $\mathrm{C}$ of the $\mathrm{CDC}$ Atlanta classification and / or CD4 in percentage (CD4\%) $<15 \%$ or stage A, B or $\mathrm{N}$ and $15 \%<\mathrm{CD} 4<20 \%$, iv) children $>5$ years CD $/ \mathrm{mm} 3<200 / \mathrm{mm} 3$ regardless of viral plasma RNA or $<200 / \mathrm{mm}^{3}<$ CD4 $<500 / \mathrm{mm}^{3}$ and viral plasma RNA $>100,000$ copies per milliliter (copies $/ \mathrm{ml}$ ), v) the allowed values of other laboratory parameters were: hemoglobin $>7 \mathrm{~g} / \mathrm{dl}$, platelets $>50,000 / \mathrm{mm}^{3}$, amylase $<2.5$ times the upper limit of normal, aspartate aminotransferase and alanine aminotransferase $<5$ times the upper limit of normal. Clinical, immunological and viral criteria were adapted to Penta guidelines ${ }^{10}$ Parents or guardians signed an informed consent to allow their children to participate in the trial.

\section{Sample Size}

Sample size was estimated aaccording to the Fleming procedure. The number of children required is estimated at 50 . This estimation based on the results of the literature using the proportion of children with HIV RNA $<400$ copies / $\mathrm{ml}$ at $\mathrm{M} 12^{11,12}$. Unilateral alternative hypothesis chose, and $5 \%$ as risk of first kind, and power of $90 \%$ were used.

\section{The standardized procedures}

Clinical examination was performed monthly. Morbidity events were recorded with a standardized questionnaire. The laboratory tests were conducted quarterly. Adherence was determined by two methods: i) a quantitative method that involved the counting of pills returned at each monthly visit. Monthly visits corresponded to the visit of replenishment of ARVs, ii) a qualitative method that consisted in questionnaire administration to parents or guardians of children quarterly. The contain of questionnaire was : identification of child's primary and secondary caregivers, caregivers' knowledge of the diagnosis, difficulties in obtaining and ARV administration, the disruption of daily life activity by the treatment and its importance, the extent to which the suggested pill administration was followed, and the reasons for missing doses.

Adverse events were collected and monitored with the rating scale of adverse events of the ANRS ${ }^{13}$

Laboratory tests (virology, immunology, hematology and biochemistry) were performed in the Centre Muraz laboratory except for HIV-1 resistance testing that was performed in the laboratoire de Bactériologie-virologie du CHU Montpellier (France). The viral plasma RNA was quantified by the technique of real-time polymerase chain reaction with a detection limit of $300 \mathrm{cp} / \mathrm{ml}$ to $0.2 \mathrm{ml}$ of plasma (Biocentric, Bandol, France ${ }^{14}$. Genotypc test was performed to determine HIV-1 subtype and drug resistance: RNA was extracted with the $\mathrm{MagNa}$ pure compact apparatus from samples containing $>1000$ HIV-1 RNA copies/ml. The interpretation of HIV-1 resistance tests was conducted based on the algorithm of the ANRS (http:/ www.hivfrenchresistance.org). FACSCountTM cytometer flow (Becton Dickinson, BD Biosciences, San Jose United States) was used to quantified the CD4 cells providing results in percentage and absolute values. Hematological parameters were obtained from the SYMEX KX21N hematology instrument (Sysmex Corporation, Kobe, Japan). The biochemistry parameters were carried out with Lisa 
300 Plus analysis (Hycel Diagnostics, Massy, France). From 2002 (give the real date) till now Centre MURAZ laboratory is usually participated with success in the UKNEQAS international program for external quality control.

\section{Drugs}

All drugs tested were provided by the Purchasing Centre of Essential and Generic drugs of Burkina Faso "CAMEG". A commitment was obtained from this Center to provide further post-trial treatment for the children who were included in the trial. The three antiretroviral drugs in the study were administered at the same time once a day. At the beginning of the study we recommended caregivers to administer drugs at $6: 00 \mathrm{pm}$ everyday because Didanosine is required to be taken in an empty stomach (so one hour before or two hours after a meal). After 15 days of treatment, the ART administration time was changed in several children from 6:00pm to 4 or 5:00 am due to the occupation of the children's caregivers. Efavirenz, (EFV) was used in the form of $200 \mathrm{mg}$ and $50 \mathrm{mg}$ according to body weight interval : between 13 to $15 \mathrm{~kg}$ we used $200 \mathrm{mg}$ per day, between $15-20 \mathrm{~kg}, 250 \mathrm{mg}$, between 20-25, 300mg, between 25-32,5,350 mg, between 32,5-40 kg $400 \mathrm{mg}$, and over $40 \mathrm{~kg} 600$ $\mathrm{mg}$. The lamivudine (3TC) was administered at a dose of $8 \mathrm{mg} / \mathrm{kg}$ per day in the form of $150 \mathrm{mg}$ tablets or syrup. DDI was administered at $240 \mathrm{mg} /$ $\mathrm{m}^{2}$ per day $(25,50,100$ or $200 \mathrm{mg}$ tablets). Only the tablet forms of DDI were available and were not entero-coated. To have a good absorption of DDI, an antacid (aluminum hydroxide-Maalox ${ }^{\circledR}$ ) was used as gastric buffer. In addition all the study children with CD $4<20 \%$ received cotrimoxazole.

\section{Main study endpoints}

The immunological efficacy was defined as the percentage of children with CD $4>25 \%$ at 24 months of treatment. The virological efficacy was defined as the percentage of children with viral plasma RNA $<300 \mathrm{cp} / \mathrm{ml}$ at 24 months of treatment. Tolerance of treatment was judged based on the frequency of clinical or biological adverse events of grades 3 or 4 in the 24 months of treatment. Viral resistance was identified from the percentage and type of mutations of HIV-1 to the 3 molecules in children with a viral plasma RNA $>1000 \mathrm{cp} / \mathrm{ml}$ during the 24 month monitoring. Adherence was measured by pill count per month and the qualitative questionnaire was used to document the quality of adherence, caregivers' opinion about drug intake quarterly, disruption of their daily activity and easiness of drug administration. The other main endpoints were: the rate of loss to follow-up, the mortality rate and frequency of the treatment interruption.

\section{Data analysis}

All the data were entered in Epi Info version 6.04. Zscores of weight for age (WAZ) and height for age (HAZ) were calculated. The mean of WAZ and HAZ were compared at inclusion, 12 months and 24 months using Student's test. The mean of CD4\%, $\mathrm{CD} 4 / \mathrm{mm} 3$ and the viral plasma RNA were compared at inclusion, M6, M12, M18 and M24 using Student's test. Quantitative variables were described either with mean, median, proportion and quartile range. Proportions were estimated with a $\mathrm{CI}$ at $95 \%$. All analyses were conducted on an intention to threat basis. The statistical significance for analyses was set at $5 \%$.

\section{Ethical Considerations}

The study protocol was reviewed and approved by the Ethics committee of the Health Research of Burkina Faso. The protocol was also recorded in the database of the clinical trials of the United States National Institutes of Health (reference NCT00122538 at www.clinicaltrials.gov).

\section{Results}

\section{Basic characteristics of patients}

The overall sample size considered for analysis was 51 children: 31 boys and 20 girls. The mean age was 6.8 years (2.5 to 15 years). The mean WAZ and HAZ were respectively -2.01 CI 95\% (-2.25 to -1.76$)$ and -2.12 IC $95 \%$ (-2.47 to - 1.77). Seventeen children were in stage A, 29 in stage B and 5 in stage C according to the CDC Atlanta classification. The median of T CD4 percentage was 8 (IQR: 6-12\%), the median of T CD4 number/mm3 was 260 (IQR: 126-566). The median of the HIV-1 plasma RNA was 5.51log10 (IQR:5.07 to $5.89 \log 10)$. At the inclusion, among the 51 children, $13.7 \%$ (7/51) were orphans of both parents, $44.2 \%(22 / 51)$ had lost either their fathers $(n=13)$ or their mothers $(n=9)$.

\section{Clinical response}

WAZ and HAZ, at 12 months of follow-upvisits, increased significantly compare to inclusion $(-1.35$ vs -2.01 and -1.46 vs $-2.12, \mathrm{p}<0.001)$. After 24 
months, WAZ and HAZ were - 1.33 and -1.25. From the inclusion to 24 months there was a gain of WAZ and HAZ, respectively 0.68 and 0.87 (p $<0.001)$. No children were lost to follow-up. Two deaths were recorded: the first from probable tuberculosis meningitis and a possible immune reconstitution inflammatory syndrome (IRIS) at 3 month and the second from severe varicella in a context of ARV resistance at 11 month. These deaths occurred at 3 and 11 months of monitoring.

About the side effect we recorded during the 24 months 72 clinical events among theses we noticed upper respiratory tract infections in 31.9\% $(23 / 72)$, lower respiratory tract infections in $29.2 \%$ $(21 / 72)$, digestive disorders in $11.1 \%(8 / 72)$, skin diseases in $9.7 \%(7 / 72)$, eye diseases in $6.9 \%(5 /$ $72)$, malaria in $5.6 \%$ (4/72), and others in 5.6\% (4 / 72). There were 3 cases of tuberculosis (Peritoneal tuberculosis, miliary tuberculosis and meningitis tuberculosis). Among these clinical events, 20 were reported severe (of grades 3 or 4) and involved 14 children. These clinical events were probably not related to treatment.

\section{Immunological efficacy}

The children with CD4 $>25 \%$ at 24 months were $67.4 \%$ (33/49) CI 95\% [54\%, 80\%]. At 24 months of treatment, the mean of CD $4 / \mathrm{mm} 3$ and CD $4 \%$ were respectively $944 / \mathrm{mm} 3$ (range 17-2238), and $28.5 \%(1-27 \%)$. We found a difference between CD 4 cells count and CD4\% at the inclusion and after 24 months follow-up $(p<0.001)$ see figure1.

\section{Virological efficacy}

At 24 months of treatment, $81.6 \%$ (40/49) IC 95\% $[68 \%, 91 \%])$ of children had an undetectable viral load (viral plasma RNA <300 cp / ml). The proportion of children with first line treatment at 24 months was $57.1 \%(28 / 49)$. The viral plasma RNA decreased significantly after six months of treatment $(\mathrm{p}<0.001)$.

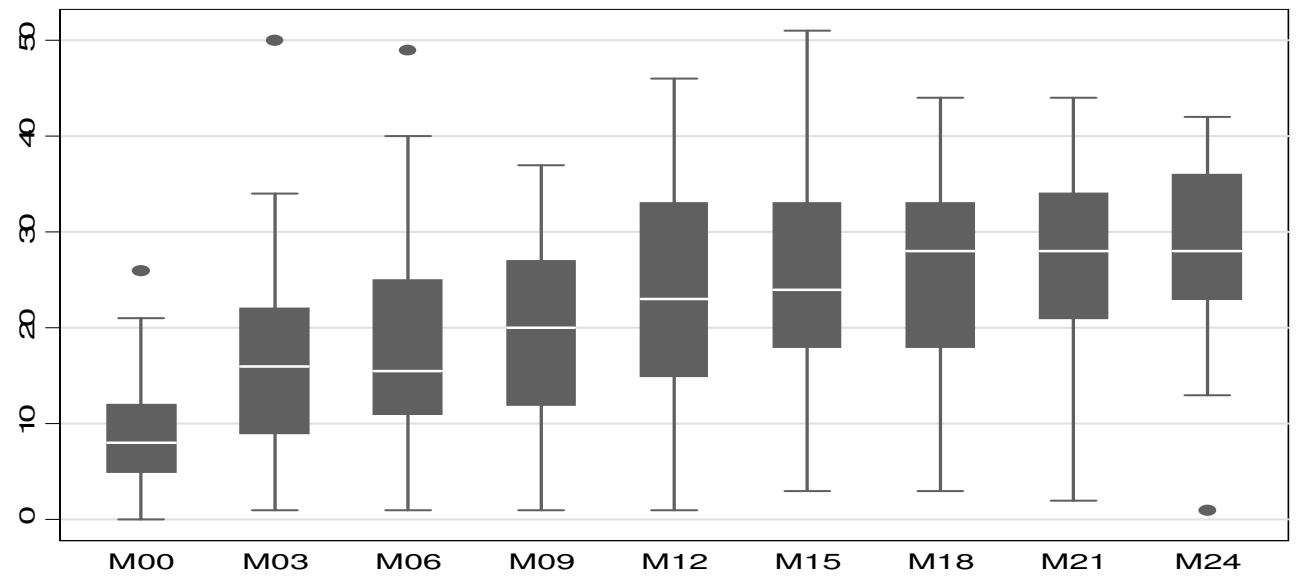

Figure 1: CD4\% during the 24 months follow-up: ANRS 12103/12167 clinical trial, Bobo-Dioulasso, Burkina Faso 2006-2008

\section{Drug tolerance}

During the 24 months, 31 biological adverse events of grades 3 or 4 were reported. A relationship with drugs for 5 adverse events was noticed, 3 cases of hyper amylasemia and 2 of hyper aspartate aminotransferase. Most of these large biological values were due to errors in medication (overdose) Two of five adverse events (2/5) were due of overdosing (one hyper amylasemia, and one hyper aspartate aminotransferase ). Reasons of these overdosing were the not understanding of clinicians instructions for drugs taking by caregivers. Children took double of doses. Drug which were incriminated were DDI for hyper amylasemia, and 3TC/EFV for hyper aspartate aminotransferase.

For these adverse events, there was one provisional treatment interruption. Treatment was re-introduced two weeks later without any concern. The other events $67.6 \%(267 / 395)$ were considered as laboratory errors. Second test on each sample was performed during two or seven day, and values 
became well. These laboratory abnormalities events occurred during all the study period.

No laboratory abnormalities were associated by clinical symptoms. Out of 96 samples, $77(80.2 \%)$ had HDL cholesterol values above normal (grade 2) for values of the normal LDL cholesterol. Table 1 show Laboratory abnormalities during the 24 months follow-up

Table 1: Laboratory abnormalities during the 24 months follow-up: ANRS 12103/12167 clinical trial, 2006-2008, Bobo-Dioulasso, Burkina Faso

\begin{tabular}{llclcr}
\hline $\begin{array}{l}\text { N= 395 analysis done } \\
\text { Abnormality }\end{array}$ & \multicolumn{2}{c}{ Patients, $\mathbf{n ~ ( \% ) ~}$} & \\
\cline { 2 - 4 } Arade2 & Grade 3 & Grade 4 & Total grade 3 and 4 \\
\hline Hemoglobin $(\mathrm{n}=395)$ & $25(6.33)$ & 0 & 0 & 0 \\
Neutrophils $/ \mathrm{mm} 3(\mathrm{n}=393)$ & $6(1.53)$ & 0 & 0 & 0 \\
platelets $/ \mathrm{mm} 3(\mathrm{n}=392)$ & $4(1.02)$ & 0 & 0 & 0 \\
Aspartate aminotransferase $(\mathrm{n}=389)$ & 0 & $1(0.25)$ & 0 & $1(0.25)$ \\
Alanine aminotransferase $\mathrm{n}=388$ & 0 & $1(0.26)$ & 0 & $1(0.25)$ \\
Amylase $(\mathrm{n}=388)$ & $45(11.60)$ & $20(5.15)$ & $1(0.26)$ & $21(5.41)$ \\
Creatinine $(\mu \mathrm{mol} / \mathrm{l}) \mathrm{n}=370$ & $8(2.16)$ & 0 & 0 & 0 \\
Low glycemia $(\mathrm{mmol} / \mathrm{l})(\mathrm{n}=386)$ & $21(5.44)$ & $4(1.04)$ & $4(1.04)$ & $8(2.08)$ \\
High glycémia $(\mathrm{mmol} / \mathrm{l})(\mathrm{n}=386)$ & $2(0.52)$ & 0 & 0 & 0 \\
Total cholesterol $(\mathrm{mmol} / \mathrm{l})(\mathrm{n}=385)$ & $37(9.61)$ & 0 & 0 & 0 \\
HDL $(\mathrm{g} / \mathrm{l}),(\mathrm{n}=96)$ & $77(80.21)$ & 0 & 0 & 0 \\
LDL $(\mathrm{mmol} / \mathrm{l})(\mathrm{n}=95)$ & $1(1.05)$ & 0 & 0 & 0 \\
Triglycerid $(\mathrm{mmol} / \mathrm{l})(\mathrm{n}=386)$ & $15(3.87)$ & 0 & 0 & 0 \\
\hline
\end{tabular}

Viral resistance

During the 24 months of treatment, 16 children had HIV-1 plasma RNA $>1000 \mathrm{cp} / \mathrm{ml}$. Eleven samples were tested. . The resistance rate at 24 month was $21.6 \%(11 / 51)$. Most of the failures occurred in the first six months of monitoring. The percentage of treatment failure was $12 \%(6 / 50)$ at 6 months. One case of failure was found after 12 months of treatment. Change of treatment was due to the virological failure and resistance documented. The main drugs used were Zidovudine (AZT), Abacavir, and Lopinavir/ritonavir as showed in table 2. The frequency of resistance to DDI was $9.1 \%(1 / 11)$, $72.7 \%(8 / 11)$ for 3TC, and $81.8 \%$ (10/11) for EFV among tested samples. Primary resistance tests were retrospectively searched on the samples of children who presented secondary resistance. No primary resistance was noticed. . In nine switched children, the HIV-1 plasma RNA became undetectable within 6 months.

\section{Treatment adherence}

The mean adherence during 24 months to the treatment was $97.1 \%$ for overall children with first and second regimen. At 24 months the adherence was $98.4 \%$. More than $88 \%$ of children had adherence $>95 \%$ during the 24 months of monitoring based on the pills counting. Administration of drugs was considered easy during the first year of monitoring according to parents or guardians. At 12 months, $89.1 \%$ of children easily took 3TC, $87.0 \%$ did with DDI, and $89.1 \%$ with EFV. In total, $10.4 \%(5 / 48)$ of the children had difficulties to take all three molecules. At 12 months of treatment, $54.4 \%$ of parents said that giving the drugs did not disrupt their lives or those of their children. The other half $(43.5 \%)$ reported that treatment disrupted their lives moderately. During this period, $95.7 \%$ reported that they always respected the instructions of medications by their children on an empty stomach. The drugs were given in $69.6 \%$ (32/46) by parents or guardians who accompanied the children to the monitoring site. In 12 additional cases, the treatments were administered to the child by another person in the family. Two (2) older children carried out the treatment on their own. These two children were among the 9 who were informed of their HIV-1 status during the first year.

At 24- month visit, the easiness drugs administration was maintained for 3TC $(93.5 \%)$, EFV (87.0\%) and DDI (79.2\%). In total, 15 children had difficulties to take medication. Four of them were in second-line treatment. The difficulties were 
linked to the form of Lopinavir/ritonavir. The tablets of this drug were too big so difficult to swallow. Some have expressed exhaustion. A 15 years-old child declared at the 24 months visit: "I'm tired of taking the drugs." Among the 15 children who showed difficulties in taking the drugs, 11 were under initial treatment. They expressed difficulties relating to the taste of DDI and/or to the important number of tablets taken per day. At 24 months of treatment only $22.9 \%(11 / 48)$ of parents reported that giving the treatments disrupted their lives and those of their children. Instructions related to medication on an empty stomach was often observed in 59.2\% (29/ $49)$ of cases and always respected in 40.8\% (20/49) of cases. In $55 \%(22 / 40)$ of cases, the treatment was given by of parents/guardians accompanying their children to the visit site

During the 24 months following -up, 12 children were informed about their HIV-1 status. The mean age of these 12 children was 11.8 years (range 7-16 years) among them three were taking the treatment themselves.

Table 2: Failure, resistance and change of regimen from DDI+3TV+EFV therapy: ANRS 12103/ 12167 clinical trial, Bobo-Dioulasso, Burkina Faso 2006-2008

\begin{tabular}{|c|c|c|c|c|c|c|c|c|c|}
\hline \multirow[t]{3}{*}{ ID } & \multirow{3}{*}{$\begin{array}{l}\text { ARN VIRAL } \\
\mathrm{CP} / \mathrm{Ml} \\
\text { (Inclusion) }\end{array}$} & \multirow{3}{*}{$\begin{array}{l}\text { Timming } \\
\text { (Month) } \\
\text { Resistance }\end{array}$} & \multirow{3}{*}{$\begin{array}{l}\text { ARN } \\
\text { Viral } \\
\mathrm{CP} / \mathrm{Ml}\end{array}$} & \multirow[t]{3}{*}{ Genotypes } & \multicolumn{3}{|c|}{ Resistances } & \multirow{3}{*}{$\begin{array}{l}\text { Interpretation } \\
\text { Algorithm ANRS } \\
\text { Resistance }\end{array}$} & \multirow[t]{3}{*}{ New Regimen } \\
\hline & & & & & \multicolumn{2}{|c|}{ Reverse Transciptase } & \multirow[t]{2}{*}{ Proteases } & & \\
\hline & & & & & NRTI & NNRTI & & & \\
\hline $\mathrm{B} 03$ & 1060000 & M6 & 10411 & CRF-02 & - & K103N & NR & EFV & $\begin{array}{l}\text { DDI+3TC+NFV } \\
(06 / 06 / 07) \text { then } \\
\mathrm{DDI}+3 \mathrm{TC}+\text { lopinarir } / 1\end{array}$ \\
\hline B05 & 2200000 & M9 & 253631 & CRF-02 & $\begin{array}{l}\text { M184I, } \\
\text { L210G }\end{array}$ & $\begin{array}{l}\text { V90I, } \\
\text { K103N, } \\
\text { V108I, } \\
\text { V179I }\end{array}$ & $\begin{array}{l}\mathrm{K} 20 \mathrm{I}, \mathrm{M} 36 \mathrm{I} \\
\mathrm{L} 63 \mathrm{P}, \mathrm{H} 69 \mathrm{~K} \\
\text { L89M }\end{array}$ & 3TC, FTC, EFV, NVP & $\mathrm{DDI}+\mathrm{ABC}+$ lopinatir $/ \mathrm{r}$ \\
\hline $\mathrm{B} 07$ & 836104 & M6 & 1090000 & $\mathrm{CRF}-02$ & $\begin{array}{l}\mathrm{M} 184 \mathrm{~V} \\
\mathrm{~K} 219 \mathrm{E}\end{array}$ & $\begin{array}{l}\text { K101P, } \\
\text { K103N }\end{array}$ & NR & 3TC, DDI, EFV, NVP & ZDV+ABC+ lopinatir $/ \mathrm{r}$ \\
\hline B09 & 111848 & M6 & 9006 & CRF-06 & $\begin{array}{l}\mathrm{M} 184 \mathrm{~V} \\
\mathrm{~K} 101 \mathrm{~N} \\
\text { V108I }\end{array}$ & - & NR & $3 \mathrm{TC}$ & $\begin{array}{l}\mathrm{ZDV}+\mathrm{DDI}+\mathrm{NFV} \text { then } \\
\mathrm{ZDV}+\mathrm{DDI}+\text { lopinatrir } / \mathrm{r}\end{array}$ \\
\hline B13 & 562516 & M6 & 144510 & CRF-02 & $\mathrm{M} 184 \mathrm{~V}$ & $\begin{array}{l}\mathrm{A} 106 \mathrm{~V}, \\
\mathrm{G} 190 \mathrm{~A} \\
\mathrm{P} 225 \mathrm{H}\end{array}$ & NR & 3TC, EFV, NVP & no change before death \\
\hline B21 & 620566 & M9 & 8983 & CRF-02 & $\mathrm{M} 184 \mathrm{~V}$ & K103N & $\begin{array}{l}\text { K20I, M336I, } \\
\text { H69K, L89M }\end{array}$ & 3TC, FTC, EFV, NVP & $\mathrm{ABC}+\mathrm{DDI}+$ lopinatir $/ \mathrm{r}$ \\
\hline B26 & 695276 & $\mathrm{M} 3$ & 1030000 & CRF-06 & $\mathrm{M} 184 \mathrm{~V}$ & $\begin{array}{l}\text { K101E, } \\
\text { G190E }\end{array}$ & NR & 3TC, EFV, NVP & $\begin{array}{l}\text { ZDV+DDI+NFV then } \\
\text { ZDV+DDI+ lopinatir } / \mathrm{r}\end{array}$ \\
\hline B33 & 1090000 & $\mathrm{M} 3$ & 212643 & CRF-02 & $\mathrm{M} 184 \mathrm{~V}$ & K103N & NR & 3TC, EFV, NVP & $\begin{array}{l}\text { ZDV+DDI+NFV then } \\
\text { ZDV+DDI+ lopinatir } / \mathrm{r}\end{array}$ \\
\hline B39 & 54369 & M9 & 5947 & CRF-02 & $\mathrm{M} 184 \mathrm{~V}$ & K103N & $\begin{array}{l}\mathrm{K} 20 \mathrm{I}, \mathrm{M} 36 \mathrm{I} \\
\mathrm{H} 69 \mathrm{~K}, \mathrm{~L} 89 \mathrm{M}\end{array}$ & 3TC, FTC, EFV, NVP & treatment no changed \\
\hline B44 & 958401 & $\mathrm{M} 3$ & 331045 & AG CRF-06 & $\begin{array}{l}\mathrm{K} 65 \mathrm{R}, \\
\mathrm{D} 67 \mathrm{G} \\
\text { (poly), } \\
\mathrm{K} 70 \mathrm{E}\end{array}$ & G190E & $\begin{array}{c}\text { I15V, } \\
\text { K20I,M36I, } \\
\text { D60S,L63P, } \\
\text { H69K, L89M }\end{array}$ & $\begin{array}{l}\text { TDF*,3TC* FTC*, } \\
\text { DDI*, ABC* EFV, } \\
\text { NVP }\end{array}$ & lopinavir/ $\mathrm{r}$ only \\
\hline B52 & $\begin{array}{c}346777 \\
(09 / 11 / 06) \\
\end{array}$ & $\begin{array}{c}\mathrm{M} 6 \\
(21 / 05 / 07) \\
\end{array}$ & 5087 & CRF- 02 & $\begin{array}{l}\text { K65N(poly) } \\
\text { T215S }\end{array}$ & $\begin{array}{l}\text { K103N, } \\
\text { M230L }\end{array}$ & $\begin{array}{l}\text { K20I, M[36I, } \\
\text { H69K, L89M }\end{array}$ & EFV, NVP & $\mathrm{DDI}+\mathrm{ABC}+$ lopinatir $/ \mathrm{r}$ \\
\hline
\end{tabular}

* Possible Resistance

\section{Discussion}

The once-a-day treatment with DDI +3TC + EFV showed good adherence (more than $88 \%$ of adherence $>95 \%$ during the 24 months). Administration of the drug was considered easy. There were good tolerance (no interruption of treatment for serious adverse events) and a good immunological and virological response at 24 months. At 24 months of treatment the mean absolute value and percentage $\mathrm{CD} 4 / \mathrm{mm} 3$ and CD $4 \%$ increased to $944 / \mu$ (range $17-2238$ ), and $28.51 \%(1-27 \%) \mathrm{p}<0.001$. The proportion of children with HIV-1 plasma RNA $<300 \mathrm{cp} / \mathrm{ml}$ at 24 months of treatment was $81.6 \%(40 / 49)$.

The virological efficacy in this study was higher than the others findings (15-18). Virological efficacy at 24 month in the similar study, Scherpbier $\mathrm{HJ}$ et al showed $67 \%{ }^{15}$. For two or three times daily Puthanakit $\mathrm{T}$ et al found $76 \%$ of virological efficacy at 18 month with EFV or NEV plus 3TC/ $\mathrm{d} 4 \mathrm{~T}$ regimen. In our study $57.1 \%(28 / 49)$ of children in the first line regimen, RNA HIV-1 were undetectable at 24 month. The reason of this low percentage of virological efficacy was due to 
resistance from 11 children during the first year of the study.

In our previous study, pharmacokinetic characteristics showed the low doses of Lamuvidine and Didanosine ${ }^{7,8}$. That could explain the virological failure occurring in this first year. This resistance conducted change of treatment. The good percentage of adherence (more than $88 \%$ ) was obtained with first line and second line treatment. We achieved a good adherence for this once-a-day regimen despite the change of treatment for 11 children. ,.

For the first time, easiness of once-a-day drug administration, the part of caregiver in this study had been documented caregivers. The aim target of antiretroviral therapy is to reduce the viral load and allow an effective immune reconstitution., But the daily activity disruption should also be a concern of to ensure a good adherence. Once-a-day treatment may be an option ${ }^{5}$. Indeed in our study $44.2 \%$ of children had lost one parent at least and were living in poor socio-economic conditions. So, once-a day treatment is a good way for them to take treatment themselves.

The choice of drugs to initiate pediatric treatment has been always problematic $c^{4}$ In our study, DDI was the drug that spared by the resistance mutations.

Tolerance was good. Among children with resistance, frequencies of these resistance were low for DDI $(9.1 \%)$, and high for 3TC (72.7\%) and EFV (81.8\%). Several choices and strategies have been suggested to introduce Lopinavir/ritonavir in first line treatment and in the prevention of mother-to-child transmission program. This regimen showed a short and long-term without toxicity. This is significant information for the safety use of this regimen. This study has a number of limitations which need to be addressed. First, the lack of control group which did not allowed for comparison. In second time, the little sample size. So, efficacy, adherence and tolerance results obtained could be underestimated. Our funding showed a good regimen for the future treatment. It could be used to treat children coming from mother-to-child transmission program in Africa. It showed also an opportunity to save new drugs which are rare in Africa.

\section{Conclusion}

Given the limited number of drugs in the African region, the weakness of monitoring in the support program' laboratories, the single dose and especially the DDI-based combination strategies could be an alternative option. However, these results need to be confirmed on a larger scale in pediatric support program.

\section{Acknowledgments}

We extend our gratitude to the children and parents or guardians who agreed to participate in this clinical trial. We also thank all the research team of the ANRS12103/12167 trial. Finally, we gratefully acknowledge the funder which is Agence Nationale de Recherches sur le Sida et les Hépatites (ANRS).

\section{Références}

1. Chiappini E, Luisa Galli L, Tovo P-A, Gabiano C, Lisi C, Bernardi S. Five-year follow-up of children with perinatal HIV-1 infection receiving early highly active antiretroviral therapy. $B M C$ Infectious Diseases 2009; 9:140

2. AIDS epidemic update. Geneva: United Nations Joint Programme on HIV/AIDS; 2009

3. Lallemant M, Jourdain G. Preventing Motherto-Child Transmission of HIV-Protecting This Generation and the Next. N Engl J Med. 2010; 363:1570-2.

4. Violari A, Cotton MF, Gibb DM, Babiker AG, Steyn J, Madhi SA et al.; CHER Study Team. Early antiretroviral therapy and mortality among HIVinfected infants. N Engl J Med 2008;359: 223344.

5. Llibre JM, Antela A, Arribas JR, Domingo P, Gatell JM, López-Aldeguer J et al. Role of fixeddose combinations of antiretrovirals in HIV-1 therapy. Enferm Infecc Microbiol Clin. 2010 Nov; 28(9):615-20.

6. Hirt D, Urien S, Olivier M, Peyrière $\mathrm{H}, \mathrm{Nacro} B$, Diagbouga $S$ et al. Is the recommended dose of efavirenz optimal in young West African human immunodeficiency virus-infected children? Antimicrob Agents Chemother. 2009;53:4407-13.

7. Hirt D, Bardin C, Diagbouga S, Nacro B, Hien $\mathrm{H}$, Zoure E et al. Didanosine population pharmacokinetics in West African human immunodeficiency virus-infected children administered once-daily tablets in relation to efficacy after one year of treatment. Antimicrob Agents Chemother. 2009;53:4399-406.

8. Bouazza N, Hirt D, Bardin C, Diagbouga S, Nacro B, Hien $\mathrm{H}$ et al. Is the recommended once daily dose of lamivudine optimal in West African 
HIV-infected children (ANRS 12103)? Antimicrob Agents Chemother. 2010; 54 : 3280-6.

9. Nacro B, Zoure E, Hien H, Tamboura T, Rouet F, Ouiminga A et al. Pharmacology and immunovirologic efficacy of once-a-day HAART in African HIV-infected children: ANRS 12103 phase II trial. Bull World Health Organ 2011;89:4518.

10. Sharland M, Blanche S, Castelli G, Ramos J and Gibbs DM on behalf of the PENTA Committee. PENTA guidelines for the use of antiretroviral therapy, 2004

11. Van Rossum AM, LA Fraaij P, de Groot R : Efficacy of highly active antiretroviral therapy in HIV-1 infected children. Lancet Infectious Diseases $2002 ; 2$ : 93-102.

12. Teglas JP, Quartier P, Treluyer JM, Urgard M, Gregoire V, Blanche S. Tolerance of efavirenz in children. AIDS $2001 ; 15: 241-3$

13. Table for grading severity of pediatric $(>3$ months of age) adverse experiences for vaccine \& Prevention Research Programs, April 1994, Division of AIDS (DAIDS)

14. Rouet F, Chaix ML, Nerrienet E, Ngo-GiangHuong N, Plantier JC, Burgard M et al. Impact of HIV-1 genetic diversity on plasma HIV-1 RNA Quantification: usefulness of the Agence Nationale de Recherches sur le SIDA second- generation long terminal repeat-based real-time reverse transcriptase polymerase chain reaction test. J Acquir Immune Defic Syndr 2007;45:380-8.

15. McKinney RE Jr, Rodman J, Hu C, Britto P, Hughes M, Smith ME, et al. Long-term safety and efficacy of a once-daily regimen of emtricitabine, didanosine, and efavirenz in HIVinfected, therapy-naive children and adolescents: Pediatric AIDS Clinical Trials Group Protocol P1021. Pediatrics. 2007;120:416-23.

16. Scherpbier HJ, Bekker V, Pajkrt D, Jurriaans S, Lange JM, TW. K: Once-daily highly active antiretroviral therapy for HIV-infected children: safety and efficacy of an efavirenz-containing regimen. Pediatrics 2007;119(3):705-15

17. Puthanakit T, Oberdorfer A, Akarathum N, Kanjanavanit S, Wannarit P, Sirisanthana T, et al. Efficacy of highly active antiretroviral therapy in HIV-infected children participating in Thailand's National Access to Antiretroviral Program. Clin Infect Dis 2005;41(1):100-7.

18. Green H, Gibb DM, Walker AS, Pillay D, Butler $\mathrm{K}$, Candeias $\mathrm{F}$ et al. Lamuvidine/abacavir maintains virological superiority over Zidovudine /lamuvidine and zidovudine/abacavir beyond 5 years in children. AIDS 2007; 21 (8):947-955. 